\title{
Duplication cyst obscuring major duodenal papilla
}

\section{Surinder Singh Rana ${ }^{a}$, Ravi Sharma ${ }^{a}$, Rajesh Gupta ${ }^{b}$}

Postgraduate Institute of Medical Education and Research (PGIMER), Chandigarh, India

A 45-year-old female presented with abdominal pain and jaundice of 3 days' duration. Her liver function tests revealed serum bilirubin of $8.6 \mathrm{mg} / \mathrm{dL}$ (conjugated: $4.6 \mathrm{~g} / \mathrm{dL}$ ). Ultrasound revealed cholelithiasis and choledocholithiasis. During endoscopic retrograde cholangiopancreatography (ERCP), a large submucosal lesion was seen in the second part of the duodenum (Fig. 1A). It was compressible with an ERCP cannula (Fig. 1A) and the papillary orifice could not be located. Endoscopic ultrasound demonstrated a multi-layered cystic structure, with cyst muscularis propria communicating with duodenal muscularis propria (Fig. 1B; arrows), suggestive of a duodenal duplication cyst. The common bile duct was seen to enter this cystic lesion. Endoscopic incision and marsupialization of the cyst was performed. Contrast injection after incision demonstrated the duplication cyst as a contrast-filled cavity (Fig. 2A). Following marsupialization, the papillary opening was identified and the common bile duct (CBD) selectively cannulated. The cholangiogram revealed a large stone obstructing the CBD. A 7-Fr stent was placed in the bile duct (Fig. 2B) and this led to the resolution of jaundice. Histological examination of biopsies from inside and outside the cyst revealed duodenal mucosa. Because of the presence of the large CBD stone the patient was referred to the surgical department for cholecystectomy and CBD exploration.

Duplication cysts are rare congenital anomalies that can occur anywhere along the gastrointestinal tract, with the duodenum being a rare site $[1,2]$. Periampullary duplication cysts are very rare and closely mimic a choledochocele. The position of the papilla helps differentiate between the two, with the papilla being on the proximal side of the bulge in the case of a duplication cyst and distal to the bulge in a choledochocele $[1,2]$. In addition, the duplication cyst is lined with duodenal mucosa containing a distinct muscle layer, whereas a choledochocele is lined by either a bile duct or a gallbladder mucosa and lacks a muscle layer $[1,2]$.

Department of a Gastroenterology (Surinder Singh Rana, Ravi Sharma); bSurgery (Rajesh Gupta), Postgraduate Institute of Medical Education and Research (PGIMER), Chandigarh, India

\section{Conflict of Interest: None}

Correspondence to: Dr Surinder Singh Rana, Professor, Department of Gastroenterology, PGIMER, Chandigarh, 160012 India, e-mail: drsurinderrana@yahoo.co.in

Received 14 March 2019; accepted 10 April 2019; published online 24 April 2019

DOI: https://doi.org/10.20524/aog.2019.0379

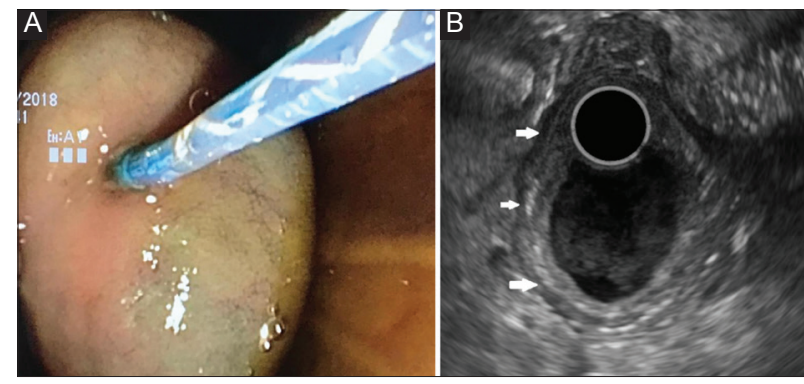

Figure 1 (A) Large submucosal lesion seen in the second part of the duodenum that is compressible with the endoscopic retrograde cholangiopancreatography cannula. (B) Endoscopic ultrasound: multi-layered cystic structure with cyst muscularis propria communicating with duodenal muscularis propria
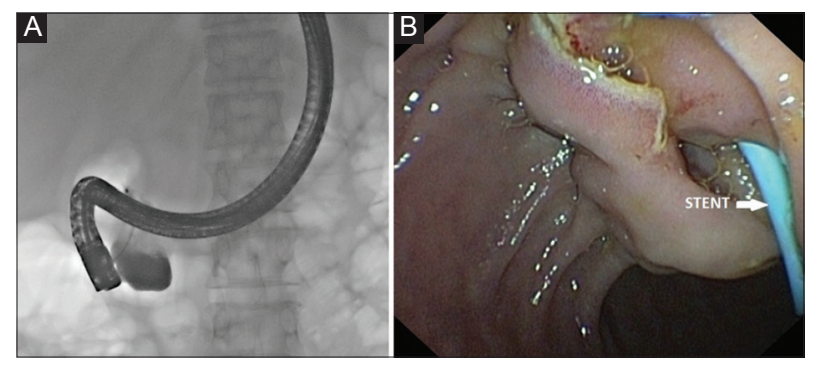

Figure 2 (A) Endoscopic retrograde cholangiography: contrast injection after incision shows the duplication cyst as a contrast filled cavity. (B) A 7-Fr stent was placed in the bile duct after endoscopic incision and marsupialization of the duplication cyst

The traditional treatment of a duplication cyst is surgery. However, successful endoscopic therapy for intraluminal duplication cysts, such as snare resection or endoscopic incision and marsupialization of the cyst, have also been reported [1-3].

\section{References}

1. Jung MK, Park SY, Jeon SW, et al. Duodenal duplication cysts of ampulla of Vater containing stone. Gut Liver 2009;3:356-359.

2. Koffie RM, Lee S, Perez-Atayde A, Mooney DP. Periampullary duodenal duplication cyst masquerading as a choledochocele. Pediatr Surg Int 2012;28:1035-1039.

3. Antaki F, Tringali A, Deprez P, et al. A case series of symptomatic intraluminal duodenal duplication cysts: presentation, endoscopic therapy, and long-term outcome (with video). Gastrointest Endosc 2008;67:163-168. 